4 Fisher JA, Ananthanarayan C, Edelit G. Role of the laryngeal mask in airway management (Editorial). Can $\mathrm{J}$ Anaesth 1992; 39: 1-3.

\section{Spontaneous reinflation characteristics of the laryngeal mask airway}

To the Editor:

The combination of heat and low pressure during sterilisation can lead to massive expansion of any residual air remaining in the laryngeal mask airway (LMA) cuff. To prevent damage, the manufacturer recommends evacuating the cuff before sterilisation to minimise residual volume, but the timing of evacuation in relation to sterilisation has not been emphasised.' The LMA cuff is permeable to nitrogen and oxygen ${ }^{2}$ and the inflated cuff spontaneously deflates. ${ }^{3}$ Similarly, a cuff evacuated to subatmospheric pressure should spontaneously reinflate. LMA cuffs may be fully evacuated several hours on the day before sterilisation. Therefore, one possible cause of cuff rupture is that, in the intervening period, the residual volume spontaneously increases above a critical level at which damage can occur. The following laboratory test was conducted to determine the spontaneous reinflation characteristics of the LMA and ascertain if there was a safe period between cuff evacuation and sterilisation.

Five \#4 LMAs were tested. All had been extensively used, had passed the preoperative checklist, and had no macro- or micro-leaks as assessed by spontaneous deflation characteristics. Each LMA was attached to a pressure transducer and three-way tap which was zeroed, calibrated and tested for leaks (Datex AS/3). The cuffs were deflated into the standard positon described for insertion, ${ }^{1}$ evacuated to $-40 \mathrm{mmHg}$ and the pressure recorded over a $24 \mathrm{hr}$ period. After $24 \mathrm{hr}$, the cuff was re-evacuated to $-40 \mathrm{mmHg}$ and the aspirated volume noted. A static pressure-volume curve was then constructed by evacuating the cuff $-40 \mathrm{mmHg}$ and inflating it with $0.2 \mathrm{ml}$ increments of air. The pressures were then converted into volumes and a volume-time curve determined. Each LMA was tested three times. In addition, the residual volume of each LMA cuff at $-40 \mathrm{mmHg}$ was calculated using a gas dilution technique.

The results show that the LMA cuff spontaneously reinflates at a decreasing rate (Figure). The mean (SD) for calculated volume increase was $1(0.2) \mathrm{ml}$ at two hours, $2.4(0.2) \mathrm{ml}$ at six hours and $5.5(0.9) \mathrm{ml}$ after $24 \mathrm{hr}$. The mean (SD) measured gas volume at $24 \mathrm{hr}$ was $5.8(0.32) \mathrm{ml}$, suggesting the reliability of the cal-

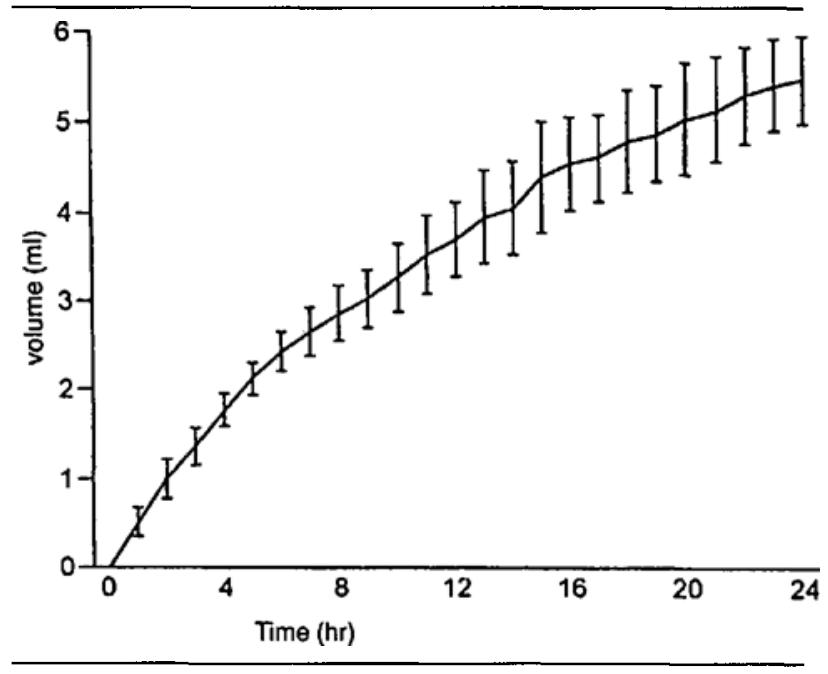

FIGURE Calculated spontaneous volume increases in the \#4 laryngeal mask airway over $24 \mathrm{hr}$ following initial evacuation to -40 $\mathrm{mmHg}$ (mean, SD)

culatoin. Mean (range) for cuff residual volume at -40 $\mathrm{mmHg}$ was $0.8(0.6-1.1) \mathrm{ml}$.

The precise risk of cuff rupture is difficult to determine since there are no data about cuff volume and damage during sterilisation at given temperatures and pressures. It has been suggested that a residual volume of $2 \mathrm{ml}$ is potentially damaging. ${ }^{4}$ If a residual volume $<2 \mathrm{ml}$ is taken as ideal then the cuff must be fully deflated within approximately two hours of sterilisation when evacuated to $-40 \mathrm{mmHg}$. This margin of safety will be less if evacuation is incomplete. The simple solution is to ensure that all LMA cuffs are fully evacuated to less than -40 $\mathrm{mmHg}$ (easily achieved by modest suction on a $20 \mathrm{ml}$ syringe) prior to autoclaving. Strict adherence to this and other guidelines ${ }^{1}$ should optimise the structural integrity of the LMA and increase patient safety.

\section{J. Brimacombe MB ChB FRCA FACA \\ Department of Anaesthesia \\ Cairns Base Hospital \\ Cairns Australia 4870}

\section{REFERENCES}

1 Brain $A I J$. The intavent laryngeal mask-instruction manual. London: Intavent, 1991.

2 Lumb $A B$, Wrigley $M W$. The effect of nitrous oxide on laryngeal mask cuff pressure. In vitro and in vivo studies. Anaesthesia 1992; 47: 320-3.

3 Brimacombe J, Berry $A$. Laryngeal mask airway cuff pressure and position during anaesthesia lasting one-two hours. Can J Anaesth 1994 (in press).

4 Biro P. Damage to laryngeal masks during sterilisation (Letter). Anesth Analg 1993; 77: 1079. 